\title{
Radiolabeling of Iranian Androctonus crassicauda Scorpion Venom with Technetium-99m for Biological Studies
}

\section{Leila Valipour Yekany}

Azad University: Islamic Azad University

Farshid Babapour Mofrad

Azad University: Islamic Azad University

Seyed pezhman Shirmardi ( $\sim$ p_shirmardi@aut.ac.ir)

NSTRI: Nuclear Science and Technology Research Institute

Mostafa Erfani

NSTRI: Nuclear Science and Technology Research Institute

Abbas Zare Mirakabadi

Razi Vaccine and Serum Research Institute

Research article

Keywords: Scorpion, Androctonus crassicauda, venom, Radiolabeling, 99mTc, Biodistribution

Posted Date: May 6th, 2021

DOI: https://doi.org/10.21203/rs.3.rs-446162/v1

License: (c) (i) This work is licensed under a Creative Commons Attribution 4.0 International License. Read Full License 


\section{Abstract}

Background: Androctonus crassicauda has a neurotoxin venom that can affect most of the vital organs of the body and result in death. In this study ${ }^{99 \mathrm{~m}} \mathrm{Tc}-\mathrm{labeling}$ and biological evaluation of Androctonus crassicauda scorpion venom are described.

Method: In this research, Toxic fraction of this venom was labelled with ${ }^{99 \mathrm{~m}} \mathrm{Tc}$. Radiochemical purity of the labelled toxic fraction was obtained by using chromatographic system. Animal biodistribution studies were performed after injection of labelled compound into normal rats.

Results: Radiochemical purity was obtained more than $90 \%$. Biodistribution studies in normal rats showed moderate clearance of blood circulation system. The results of the study indicated that scorpion venom labeling with ${ }^{99 \mathrm{~m}} \mathrm{Tc}$ can be a useful tool for the biodistribution and kinetic studies of the venoms for clinical use.

\section{Introduction}

Scorpion stings are among the most important health and medical issues in the world. This is especially important in underdeveloped tropical and subtropical countries where thousands of lives are at risk of death each year. Scorpion venom may cause drastic medical complications and early death if injected into the body. Neurotoxins are the most important components of scorpion venom that are responsible for the pathological appearance of envenoming. Apart from neurotoxins, a vast range of other molecules can be found in their venoms. Developments in purification, separation methods, and labeling approaches has enabled not only the effective treatments against envenoming, but has also resulted to the discovery of several scorpion venom biomolecules with therapeutic properties. Consequently, scorpion venom may not only be a threat for human health, but could prove to be a important source of bioactive molecules against future diseases.

According to World Health Organization (WHO), about 2000-3000 deaths due to scorpion sting envenoming are reported annually worldwide (WHO, 2018).

Up to now, more than 2000 scorpion species have been introduced. The most dangerous scorpion species to humans belong to the Buthidae family, but some scorpion in the Hemiscorpiidae and Scorpionidae families have also been classified as hurtful (Laustsen, 2016 and Lourenço, 2018).

In Iran, scorpion stings are among the most important health and medical issues. Annually 40,000 to 50,000 scorpion sting are reported to take place in Iran (Kassiri etal., 2021 and Dehghani, 2012).

Due to the importance of scorpion stings and its dangers to humans, scorpion venom researches have long been of interest to researchers. Scorpion species in Iran include scorpionidae and buthidae which are classified into 25 species and 16 genera (Shahbazzadeh et al., 2003). 
Andractonus crassicauda scorpion is one of the most dangerous scorpions in the world. Its natural habitat is arid and tropical, and it is widely spread in Iran. This kind of scorpion belongs to the Butide family and has neurotoxic toxin. If this scorpion bites a human, it will affect most of the vital organs and will result in death (Radmanesh, 1990). The content and toxicity of scorpion venom varies from species to specie (Borges et al., 2006). Scorpions' venom of the same species also differs in its levels of protein and toxicity (Kalapothakis, 1997).

The difference in the amino acid sequences of each venom causes action and immunological differences of the venom (Gwee et al., 1996). There is not enough information available about the mechanism, function and biological distribution of scorpion venom in humans and animals bodies. In fact, to improve the treatment of scorpion sting, biological function of the venom needs to be studied. Also, knowing the organ distribution is important for clinical purposes.

Although clinical manifestations of Iranian Androctonus crassicauda scorpion venom have been investigated in experiments (Radmanesh, 1990 and Dehghani et al., 2006), the biological distribution of the toxin of this kind of scorpion has not been reported for clinical purposes so far. A great approach to analyze the biological distribution of an unknown substance such as scorpion venom in different organs is to label it with radionuclides. Understanding the biological distribution and concentration of the scorpion venoms in different organs could be useful for preparation of better antivenom for clinical application.

So far, labeling animal venom with radionuclides has rarely been reported, but research has shown excellent results in tissue distribution, pharmacokinetics, channel ionic binding, neuropharmacological and neurobiochemical.

As a result, it has provided the researchers with the ability to produce potent anti-toxins and treat many diseases, especially different types of cancers. Examples of research conducted in recent years include:

In 1998, Ismail et al., studied the pharmacokinetics of the scorpion venom Androctonus amoreuxi labelled with ${ }^{125} \mathrm{I}$ in rabbits. Their results showed that the destructive effects of scorpion sting were not related to the venom concentration in the organs and the failures were due to indirect factors (Ismail, 1998).

In 2002, Nunan et al., labeled titustoxin and venom from the scorpion Tityus serrulatus with ${ }^{99 \mathrm{~m}} \mathrm{Tc}$.

Titustoxin is the most important toxic fraction of the scorpion venom Tityus serrulatus, which is used as a tool for neuropharmacological and neurobiochemical studies. In their study, the biological activity of titustoxin and scorpion venom was compared in a labeled and un-labeled condition. The results showed that the biological activities of titustoxin and scorpion venom continue after labelling (Nunan et al., 2002).

In 2010, Shirmardi et al., investigated the biodistribution of Mesobuthus eupeus scorpion venom fractions labeled with Tc-99m in animals (mouse). In the venom of this scorpion, there are several toxic fractions 
that can affect ion channels. Results of that study showed rapid blood clearance of labeled compound (Shirmardi et al., 2010).

In 2012, Seyedian et al., examined tissue distribution of Hemiscorpius lepturus scorpion venom and antivenom polyclonal. The results of the comparison pharmacokinetic parameters and tissue distribution of venom and antivenom showed that serotherapy has better effects when performed 2-4 hours after scorpion sting (Seyedian et al., 2012).

In 2015, Asad et al., studied the biodistribution and kinetic of Naja Naja karachiensis venom, labeled with ${ }^{99 m} \mathrm{mc}$, using the SPECT imaging system. The results showed that the lungs and liver are the main sites of toxin metabolism and the kidneys are the main organ of toxin excretion (Asad et al., 2015).

In 2016, Vergara et al., investigated the tissue distribution and tracking of B-neurotoxins (B-NTx) labeled with ${ }^{67} \mathrm{Ga}$ using molecular imaging. B-NTx is the most important fraction of eastern coral snake poison Micrurus fulvius. Respiratory paralysis in patients bitten by Micrurus fulvius snake is attributed to Bneurotoxins.The results showed that the lymphatic system has a key role in the biological distribution of B-NTx-DTPA- ${ }^{67} \mathrm{Ga}$ (Vergara et al., 2016).

In 2018, Shirmardi et al., examined the biodistribution of peptide extracted from the venoms of an Iranian brown snake and a yellow scorpion (ICD-85) labeled with ${ }^{99 \mathrm{~m}} \mathrm{Tc}$ for imaging and treating tumor. The results showed that the labeling yield was satisfactory and the liver, kidney and the tumor were the targets of ICD-85 venom. Also, the clearance of the labeling compound from the blood circulatory system was moderate (Shirmardi et al., 2018).

In 2019, Díaz-García et al., examined the pharmacokinetics and biological distribution of Rhopalurus junciuc scorpion venom labeled with ${ }^{131}$ I in tumor-bearing mice by intravenous and oral administration. Recent research has shown that Rhopalurus Junciuc scorpion venom has an anti-tumor effect. The results showed that the pharmacokinetic and biological distribution of the ${ }^{131}$ I-venom compound in tumor-bearing mice depended on the method of administration and also the presence of the ${ }^{131}$ I-venom compound in the tumor tissue was longer than that of the main organs (Díaz-García et al., 2019).

${ }^{99 m} \mathrm{Tc}$ is selected as the ideal radiotracer for many experimental studies and nuclear medicine procedures.

The superiority of ${ }^{99 \mathrm{~m}} \mathrm{Tc}$ is because of its proper nuclear properties. These properties include a short halflife of 6 hours and photon energy of $140 \mathrm{keV}$, which makes ${ }^{99 \mathrm{~m}} \mathrm{Tc}$ suitable for high-efficiency detection and consequently low radiation exposure (Banerjee, 2001).

In this study, toxic fraction of Androctonus crassicauda scorpion venom was labeled with ${ }^{99 \mathrm{~m}} \mathrm{Tc}$, and biological distribution, and target organs of the labeled compound were evaluated in normal rats.

\section{Materials And Methods}


All chemical materials were prepared from Fluka and Sigma companies. TLC model is an AR 2000 (North America Bioscan). Sodium pertechnetate $\left(\mathrm{Na}^{99 \mathrm{~m}} \mathrm{TcO}_{4}\right)$ was purchased from commercial ${ }^{99 \mathrm{~m}} \mathrm{Mo} /{ }^{99 \mathrm{~m}} \mathrm{Tc}$ Generator.

Toxic fractions of Androctonus crassicauda scorpion venom were prepared in lyophilized state from Razi Vaccine and Serum Research Institute in Karaj.

\subsection{Venom preparation}

Androctonus crassicauda crude venom was obtained from Iranian Androctonus crassicauda. After collecting the scorpions by using ultra-violet lamp at night on the southwestern of Iran, they were milked by electrical stimulation of the telson at the end of tail. After that, milked venom dissolved in distilled water and centrifuged for removing the mucoproteins. $0.45 \mu \mathrm{m}$ filter and

Nanodrop spectrophotometer were used to filter supernatant and determine protein concentration, respectively.

The filtered venom was loaded on a sephadex G-50 column (chromatography). The column was eluted with ammonium acetate $(0.1 \mathrm{M})$, at $40 \mathrm{ml} / \mathrm{h}$ flow rate. The column elution diagram showed nine peaks (F1-F9). Peak of F5 was toxic fraction against mice and used for radiolabeling (Bayatzadeh, 2020).

\subsection{Labeling and radiochemical analysis of toxic fraction}

More than $80 \%$ of the clinical radiopharmaceuticals are Technetium- $99 \mathrm{~m}$ based, as mentioned above, the reasons for high usage of this radiopharmaceuticals are the ease of availability and optimal nuclear characteristics such as short half-life, acceptable gamma energy for producing good quality images. Moreover ${ }^{99 \mathrm{~m}} \mathrm{Tc}$ is readily available from a generator of ${ }^{99} \mathrm{Mo} /{ }^{99 \mathrm{~m}} \mathrm{Tc}$ at low cost and high quality.

In this study, direct labeling method was chosen, and for this, stannous chloride was used as the reducing agents (Pauwels, 1993 and Pujatti et al., 2005). Preliminary researches by authors were carried out to establish the optimum conditions to obtain the highest yield from labeling the mentioned fraction. Briefly, $60 \mu \mathrm{g}$ of the toxic fraction was dissolved in 60 microliters of water (distilled) and then adjusted to $\mathrm{pH}=$ 7.5 by adding $100 \mu$ l of PBS $(0.1 \mathrm{M}, \mathrm{pH}=7.4)$.

The sample product was mixed by a shaker for 10 minutes at room temperature. Also a certain amount of $\mathrm{SnCl}_{2}(2,5,10,20,30$ or $50 \mu \mathrm{g})$ was dissolved in double distilled water $(0.1 \mathrm{normal} \mathrm{HCl}$ was used to completely dissolve stannous chloride in double distilled water) then it was transferred into a vial containing toxic fraction.

Finally, $\mathrm{Na}^{99 \mathrm{~m}} \mathrm{TcO}_{4}(140.6 \mathrm{MBq})$ freshly milked from a generator of ${ }^{99} \mathrm{Mo} /{ }^{99 \mathrm{~m}} \mathrm{Tc}$ was added to the vial for reaction. This mixture were shacked for $1 \mathrm{~min}$ and kept for $12 \mathrm{~min}$ at room temperature for doing the reaction (Boletini-Santos,2008 and Murugesan et al., 1999). 
To obtain a more purified labeled toxic fraction, it was loaded on a gel chromatography column (G-25 sephadex), and the column was washed with PBS. Finally, $1 \mathrm{ml}$ fractions were collected and counted by well- type gamma counter.

Then, all of the collected $1 \mathrm{ml}$ volumes with high count were mixed together. Then, radiochemical yield of labeled toxic fraction were determined by TLC (Whatman paper No.1). As a mobile phase, acetone was

used for this system $\left({ }^{99 \mathrm{~m}} \mathrm{TcO} 4^{-} \mathrm{Rf}=1,{ }^{99 \mathrm{~m}} \mathrm{Tc}\right.$-colloid and labeled compound $\left.\mathrm{Rf}=0\right)$. The radioactivity was measured by cutting the whatman strip $(10 \mathrm{~cm})$ into $1 \mathrm{~cm}$ pieces and counting in a well type counter.

\section{3. ${ }^{99 \mathrm{~m}} \mathrm{Tc}$ - toxic fraction stability}

For stability study in human serum, $50 \mu \mathrm{l}$ of the labeled toxin added to $1 \mathrm{~mL}$ of fresh human serum at $37^{\circ} \mathrm{C}$ temperature up to $4 \mathrm{~h}$. Stability study in PBS was performed by incubating $50 \mu \mathrm{l}$ of the labeled toxic fraction with $1 \mathrm{ml}$ PBS solution storing for $4 \mathrm{~h}$ at room temperature. For stability analysis, TLC method was performed

\subsection{Biological distribution study}

Animal studies were done in compliance with the regulations of NSTRI and with generally accepted guidelines governing such work.

Male rats, weighing $200-250 \mathrm{~g}$, were injected with $11.1 \mathrm{MBq}(300 \mu \mathrm{Ci})$ of radiolabeled toxic fraction in saline via the tail vein. The amount of injected activity into each rat was measured by counting the 1-ml syringe before and after injection in a dose calibrator with fixed conditions. Finally, animals were killed by $\mathrm{CO}_{2}$ after $15 \mathrm{~min}, 45 \mathrm{~min}$ and $4 \mathrm{~h}$ and internal organs were dissected, weighted and counted for radioactivity measurement. Organ activities were converted and expressed as the percentage of injected dose per gram of tissue $(\% / \mathrm{I} / \mathrm{g})$.

\section{Result}

\subsection{Labeling toxic fraction with ${ }^{99 \mathrm{~m}} \mathrm{Tc}$ and radiochemical analysis}

Toxic fraction of Androctonus crassicauda scorpion venom was labeled with ${ }^{99 \mathrm{~m}} \mathrm{Tc}$ by direct labeling method. In order to obtain the optimal radiochemical purity, various values of $\mathrm{SnCl}_{2}$ were checked. 2, 5, $10,20,30$ and 50 microgram of freshly dissolved $\mathrm{SnCl}_{2}$ in $\mathrm{HCl}$ under nitrogen blanket were used for reducing process and the most radiochemichal yield was obtained by using 10 microgram $\mathrm{SnCl}_{2}(90 \%)$ (Fig. 1.). Figures $2-4$ shows chromatography tests of labeled toxin (using 10 microgram $\mathrm{SnCl}_{2}$ ) by G-25 Sephadex column, TLC and HPLC for radiochemical purity analysis.

\section{2. ${ }^{99 m} \mathrm{Tc}-$ toxic fraction stability}


Radiochemical stability analysis of labeled toxic fraction in human fresh serum and PBS showed that the radiochemical purity remained about $47 \%$ and $55 \%$ after 4 hours respectively.

\subsection{Biological distribution studies}

Figure (5) summarizes the biodistribuion and kinetic for labeled compound in different organs. This model analysis facilitates the visualization of the labeled compound biodistribution profiles during the distribution, metabolism and excretion. Also, figure (6) shows the scintigraphic images of animal after 15 minutes and 45 minutes post injection of labeled compound.

\section{Discussion}

\subsection{Toxic fraction radiolabeling with ${ }^{99 \mathrm{~m}} \mathrm{Tc}$, radiochemical analysis and stability}

Venom is the remarkable source of poly peptide with different kinds of actions. Most of the envenomations by scorpions in Iran, are caused by Buthidae family scorpions, and 41 percent of the cases belong to Androctonus scorpions (Jolodar, 2019). Scorpion venoms can contain an wide range of small peptide toxins which can be categorized into two types, namely disulfide-bridged peptides and nondisulfide-bridged peptides (Jolodar, 2019). Disulfide-bridged peptides are interesting peptides to research and clinical applications.

As mentioned, an interesting way to see the biological distribution and the organic concentration of scorpion venom is to label it with radionuclides.

${ }^{99 m} \mathrm{Tc}$ is pioneer in nuclear medicine research because of its ideal nuclear properties. These ideal nuclear properties are: half-life of 6 hours, gamma ray energy $140 \mathrm{keV}$, ease of access from a generator of ${ }^{99} \mathrm{Mo} /{ }^{99 \mathrm{~m}} \mathrm{Tc}$ and well established labeling chemistry(Banerjee, 2001). There are three main methods of 99m Tc labeling: direct labeling, chelate approach and indirect labeling (Liu et al., 1997 and Gandomkar et al., 2003). Because of disulfide binds in proteins and their fragments, the direct method of labeling is usually used.

The direct labeling method usually does not require synthetic modification and is applied to heavy peptides, proteins and their fragments because of their disulfide bonds. Direct labeling method does not require synthetic modification and is easy to perform.

In direct method, the reducing agent is used to change the number of disulfide binds to free thiols, which are able to bind the ${ }^{99 \mathrm{~m}}$ Tc very efficiently. In the present study, $\mathrm{SnCl}_{2}$ was used as a reducing agent and the results showed that the labeling yield was more than $90 \%$ and the labeled toxic fraction demonstrated considerable radiochemical stability. According to the present results and the previous studies, it can be mentioned that this method (direct labeling) can be an acceptable method to radiolabel the venoms.

\subsection{Biological distribution studies}


The result of biodistribution in the rats showed that the initial level of labeled toxic fraction in the blood decreased from $1.95 \%$ at 15 minutes to $0.02 \%$ at $4 \mathrm{~h}$ post injection, which was an indication of the moderate clearance of labeled compound from the circulation system of blood.

These results also showed a concentration of activity in the liver decreased from $2.59 \%$ at 15 minutes to $0.03 \%$ at $4 \mathrm{~h}$ post injection, and in kidneys from $1.77 \%$ at 15 minutes to $0.11 \%$ at $4 \mathrm{~h}$ after labeled compound injection.

Based on these results, we conclude that the possible site for metabolism of venom is liver, and kidneys are main organs of excretion in rats.

Brain activity was $0.05 \%$ at 15 minutes post injection indicating that the labeled compound can pass through the bl ood brain barrier.

Thyroid and stomach uptake level was low indicating good quality of the radiolabeled compound, although the two main target organs in the body are thyroid and the stomach after ${ }^{99 \mathrm{~m}} \mathrm{TcO}_{4}{ }^{-}$injection.

${ }^{99} \mathrm{mcO}_{4}{ }^{-}$active uptake by these two organs can be used as a physiological indicator of the radiochemical purity preparation.

\section{Conclusion}

Labeling the toxic fraction with ${ }^{99 \mathrm{~m}} \mathrm{Tc}$ was successfully performed by using stannous chloride as a reducing agent.

The labeling yield was $>90 \%$ and the labeled compound had good radiochemical stability.

The results of this study indicate that toxin labeling with ${ }^{99 \mathrm{~m}} \mathrm{Tc}$ is a useful tool invivo study and includes an excellent method for monitoring the biological distribution process of toxin for clinical purposes.

\section{Declarations}

\section{Acknowledgement}

The authors wish to thank all staff of the institute and the radiation application school for their contribution in the research and also Mr. Mazidi, Mr. Parayandeh Mr. Goodarzi and Mr. Karami for their cooperation and Mr. Amoosi to edit the english grammar.

We would like to thank Yasser Amoosi for offering help in reviewing and revising the manuscript for grammar and syntax.

\section{Authors'contributions}


LVY, FBM, SPS, ME and AZM designed the study. LVY, SPS, ME, and AZM collected the data. LVY processed the data. LVY, FBM and SPS interpreted the data. SPS drafted and revised the manuscript. All authorsread and approved the final manuscript.

\section{Funding}

Not applicable

\section{Availability of data and materials}

The datasets used and analysed during the current study are available from the corresponding author on reasonablerequest.

\section{Ethics approval and consent to participate}

Animal experiments were performed in compliance with the regulations of our institution and with generally accepted guidelines governing such work.

\section{Consent for publication}

Not applicable

\section{Competing interests}

The authors declare that they have no competing interests

\section{References}

Asad, B., et al., Biodistribution and kinetic studies of technetium-99m labeled Naja naja karachiensis venom via gamma scintigraphic and SPECT images. Pakistan journal of pharmaceutical sciences, 2015. 28(4).

Banerjee, S., M.R.A. Pillai, and N. Ramamoorthy. Evolution of Tc-99m in diagnostic radiopharmaceuticals. in Seminars in nuclear medicine. 2001. Elsevier.

Bayatzadeh, M.A, Zare Mirakabadi, A., Babaei, N., Doulah, A.H., Doosti, A.,. Characterization, molecular modeling and phylogenetic analysis of a long mammalian neurotoxin from the venom of the Iranian scorpion Androctonus crassicauda. Biologia , 2020.75, 1029-1041. https://doi.org/10.2478/s11756-01900400-1.

Boletini-Santos, D., et al., Systemic response induced by Scorpaena plumieri fish venom initiates acute lung injury in mice. Toxicon, 2008. 51(4): p. 585-596.

Borges, A., et al., Diversity of long-chain toxins in Tityus zulianus and Tityus discrepans venoms (Scorpiones, Buthidae): molecular, immunological, and mass spectral analyses. Comparative 
Biochemistry and Physiology Part C: Toxicology \& Pharmacology, 2006. 142(3-4): p. 240-252.

Dehghani, R. and B. Fathi, Scorpion sting in Iran: a review. Toxicon, 2012. 60(5): p. 919-933.

Dehghani, R., T. Khamehchian, and M.A. Asadi, Surveying the effect of Androctonus crassicauda venom on clinical manifestations in rats. KAUMS Journal (FEYZ), 2006. 10(2): p. 17-20.

Díaz-García, A., et al., Pharmacokinetics and Biodistribution of Rhopalurus junceus Scorpion Venom in Tumor-Bearing Mice after Intravenous and Oral Administration. Iranian biomedical journal, 2019. 23(4): p. 287.

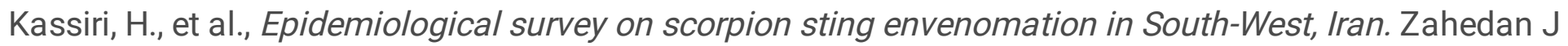
Res Med Sci, 2021. 14(8): p. 80-83.

Gandomkar, M., et al., Direct labelling of octreotide with 99mTc: effect of different concentration of reducing agents and amount of sodium pertechnetate on radiolabelling efficiency. Applied radiation and isotopes, 2003. 58(3): p. 361-364.

Gwee, M., et al., Studies on Venoms from the Black Scorpion Hetero-Metrus Longimanus and Some Other Scorpion Species. Journal of Toxicology: Toxin Reviews, 1996. 15(1): p. 37-57.

Ismail, M. and M. Abd-Elsalam, Are the toxicological effects of scorpion envenomation related to tissue venom concentration? Toxicon, 1998. 26(3): p. 233-256.

Jolodar, A. Molecular Characterization of a Three-disulfide Bridges Beta-like Neurotoxin from Androctonus crassicauda Scorpion Venom. Archives of Razi Institute, 2019. 74(2): 135-142. doi:

10.22092/ari.2018.105829.1028.

Kalapothakis, E. and C. Chávez-Olórtegui, Venom variability among several Tityus serrulatus specimens. Toxicon, 1997. 35(10): p. 1523-1529.

Laustsen, A.H.; Solà, M.; Jappe, E.C.; Oscoz, S.; Lauridsen, L.P.; Engmark, M. Biotechnological Trends in Spider and Scorpion Antivenom Development. Toxins 2016, 8, 226.

Lourenço, W.R. The evolution and distribution of noxious species of scorpions (Arachnida: Scorpiones).

Venom. Anim. Toxins Incl. Trop. Dis. 2018, 24.

Murugesan, S., et al., LABELLING, BIODISTRIBUTION AND SCINTIIMAGING. J. Venom. Anim. Toxins, 1999 : p. 35-46.

Liu, S., D.S. Edwards, and J.A. Barrett, 99mTc labeling of highly potent small peptides. Bioconjugate chemistry, 1997. 8(5): p. 621-636. 
Nunan, E., V. Cardoso, and T. Moraes-Santos, Technetium-99m labeling of tityustoxin and venom from the scorpion Tityus serrulatus. Applied radiation and isotopes, 2002. 57(6): p. 849-852.

Pauwels, E., et al., The labeling of proteins and LDL with 99mTc: a new direct method employing KBH4 and stannous chloride. Nuclear medicine and biology, 1993. 20(7): p. 825-833.

Pujatti, P.B., C.J.R. Simal, and R.G.d. Santos, Preparation of crotalus venom radiolabeled with technetium99m as a tool for biodistribution study. Brazilian Archives of Biology and Technology, 2005. 48(SPE2): p. 9-12.

Radmanesh, M., Androctonus crassicauda sting and its clinical study in Iran. The Journal of tropical medicine and hygiene, 1990. 93(5): p. 323-326 .

Shirmardi, S.P., et al., Preparation and biodistribution study of a 99mTc-labeled toxic fraction of Iranian mesobuthus eupeus scorpion venom. 2010.

Seyedian, R., et al., A biodistribution study of Hemiscorpius lepturus scorpion venom and available polyclonal antivenom in rats. Journal of Venomous Animals and Toxins including Tropical Diseases, 2012. 18(4): p. 375-383 (2012).

Shahbazzadeh, D., et al., Epidemiological and clinical survey of scorpionism in Khuzestan province, 2003, Iran.

Shirmardi, S.P., et al., Radiolabeling the Peptides extracted from Scorpion venom (ICD-85) with 99mTC as treatment and imaging agent for cancer. Iranian Journal of Medical Physics, 2018. 15(Special Issue-12th. Iranian Congress of Medical Physics): p. 357-357.

Vergara, I., et al., Biodistribution and lymphatic tracking of the main neurotoxin of Micrurus fulvius venom by molecular imaging. Toxins, 2016. 8(4): p. 85.

WHO. Report of the Eleventh Meeting of the WHO Strategic and Technical Advisory Group for Neglected Tropical Diseases; World HealthOrganization: Geneva, Switzerland, 2018; p. 1-28.

\section{Figures}

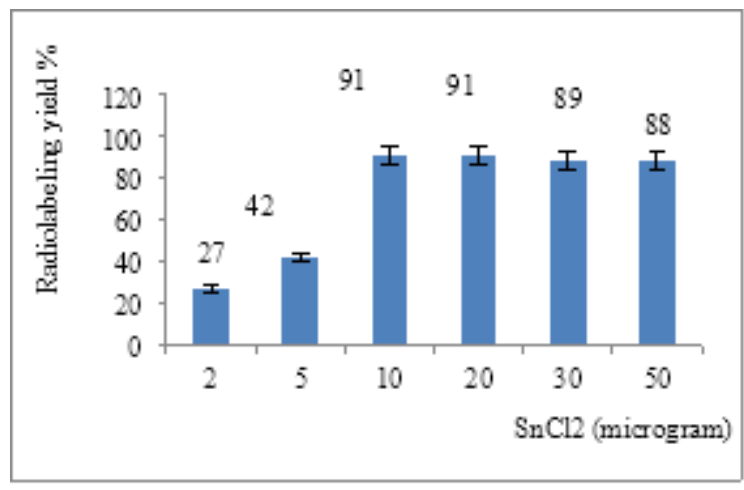


Figure 1

Radiolabeling yield percentage versus $\mathrm{SnCl} 2$ values

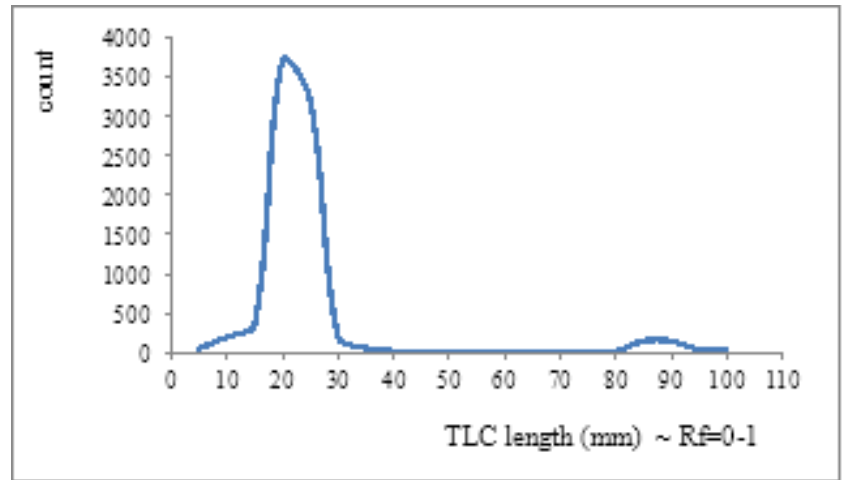

Figure 2

TLC diagram of 99mTc-toxin fraction

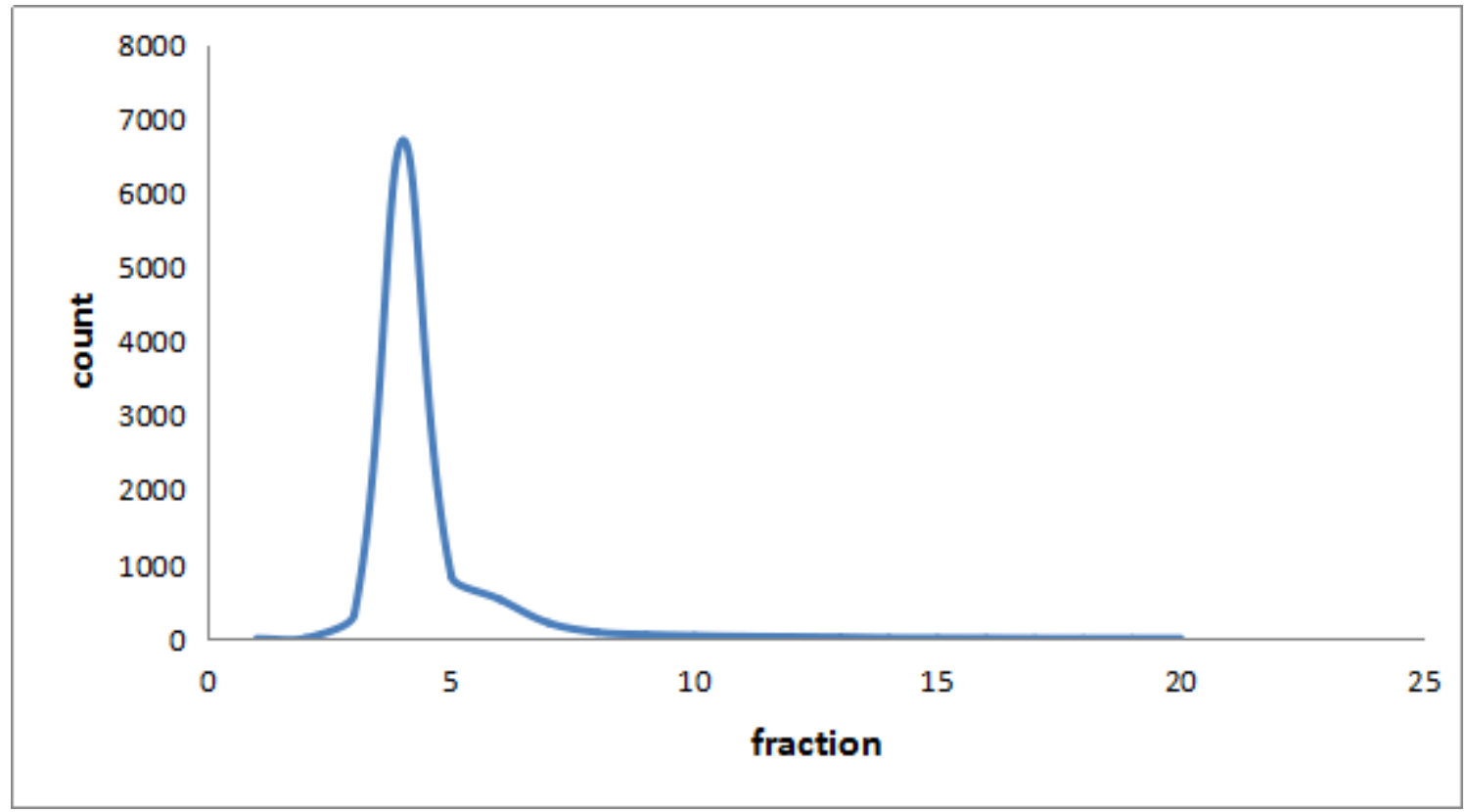

Figure 3

Gel filtration chromatography analysis with sephadex G-25 for purification of $99 \mathrm{mTc}$-toxic fraction 


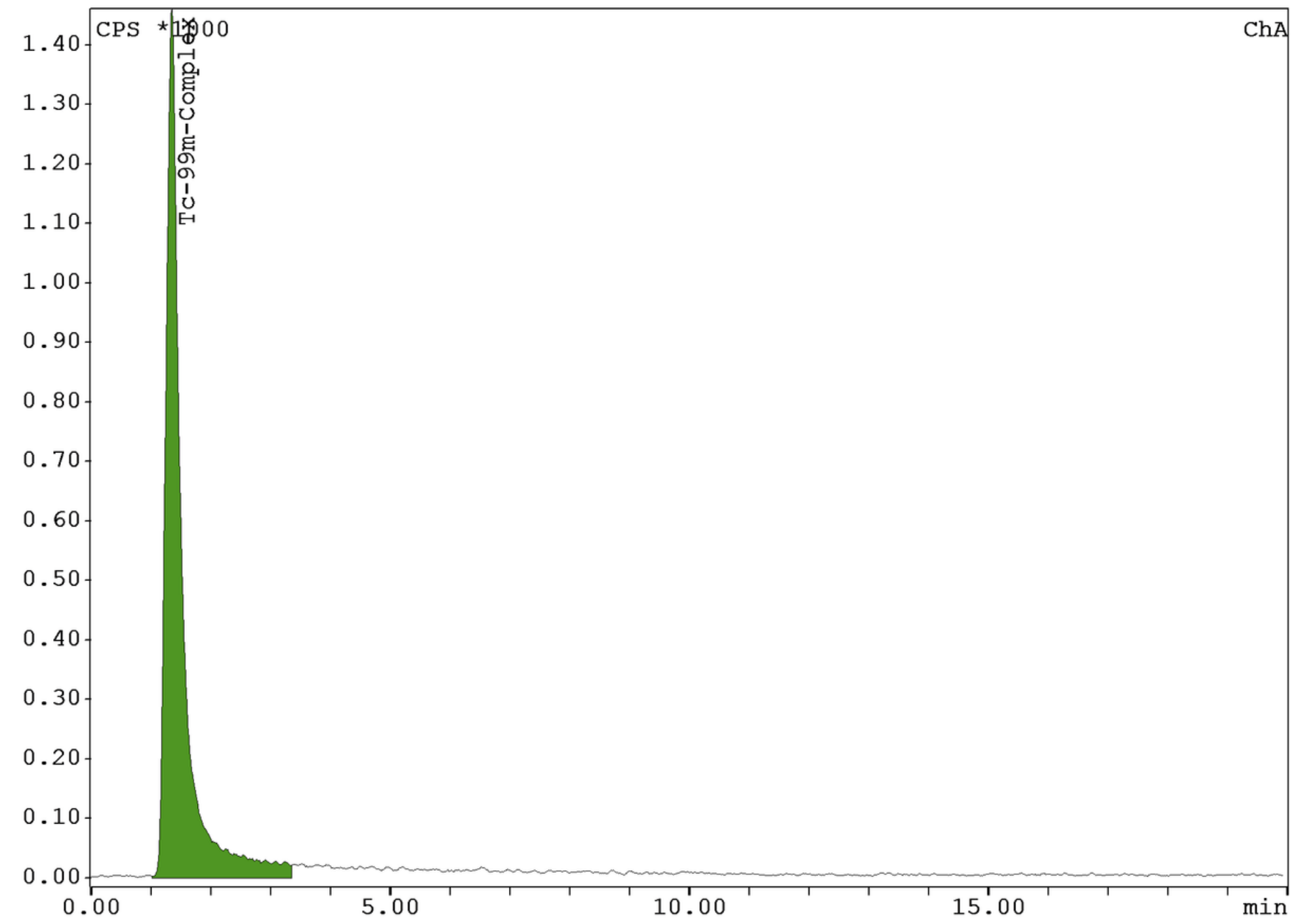

Figure 4

RP-HPLC of 99mTc-toxin fraction after purification by Gel filteration 


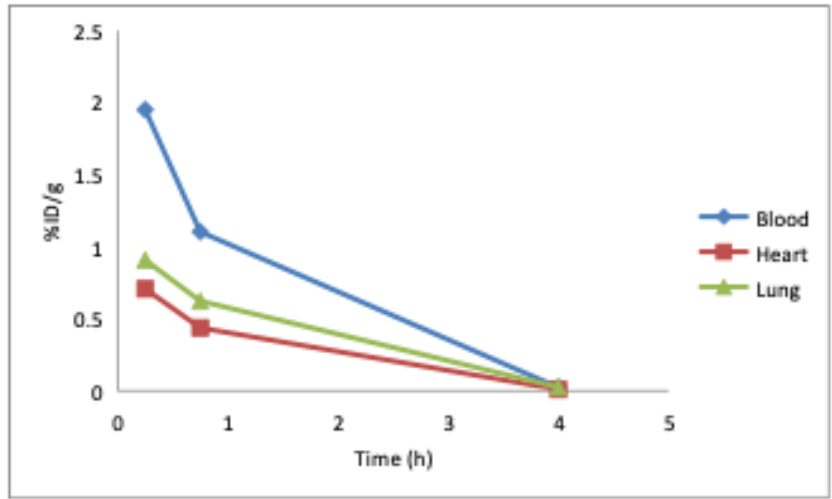

$(5-a)$

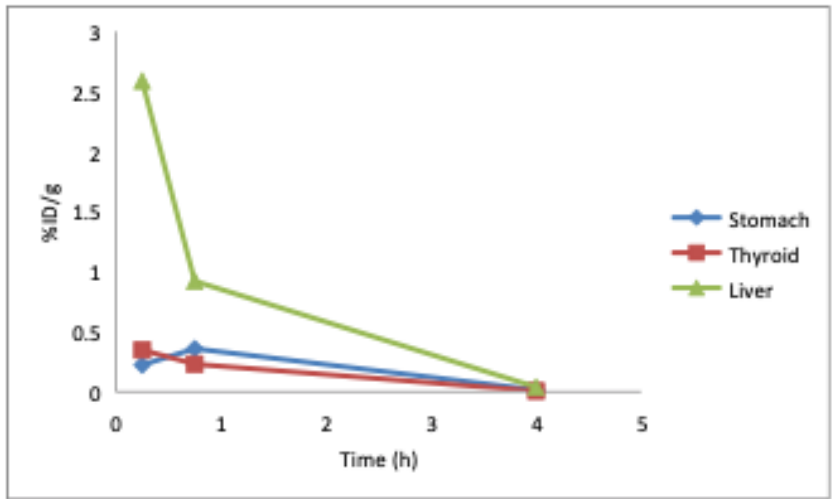

$(5-b)$

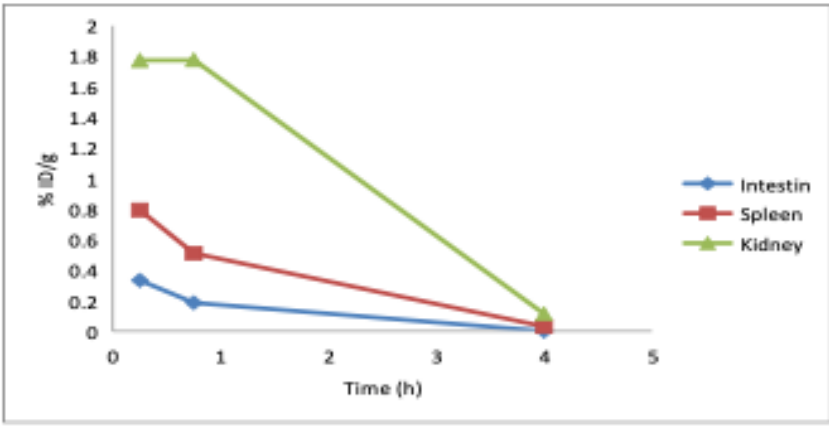

$(5-c)$

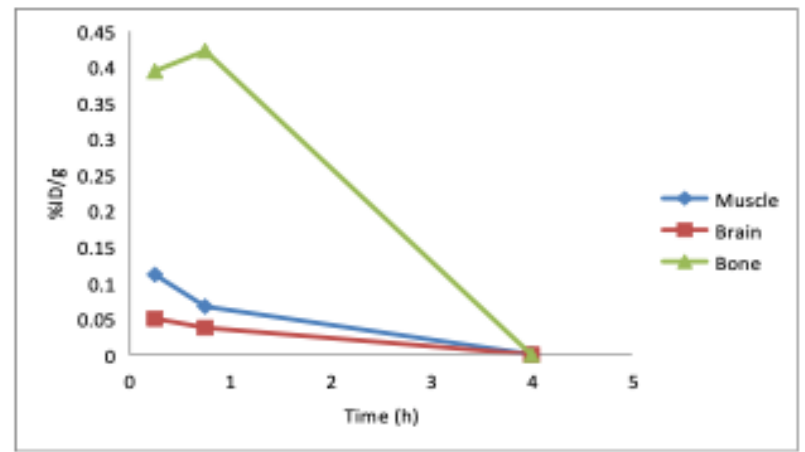

$(5-d)$

\section{Figure 5}

(a-d) Labeled toxic fraction biodistribution and kinetics behavior in each organs and blood sample over 4 hours after intravenous administration. Data is expressed as the percentage of total injection dose per tissue weight $(\% \mathrm{ID} / \mathrm{g})$. 


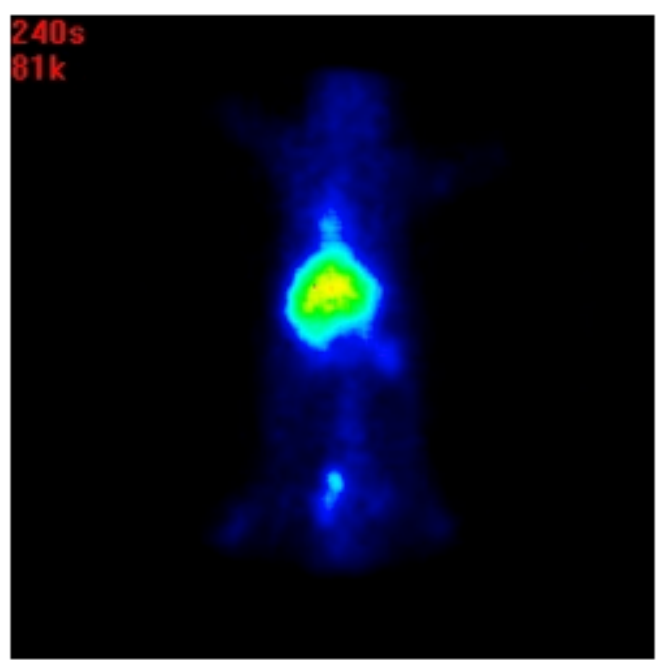

(6-a)

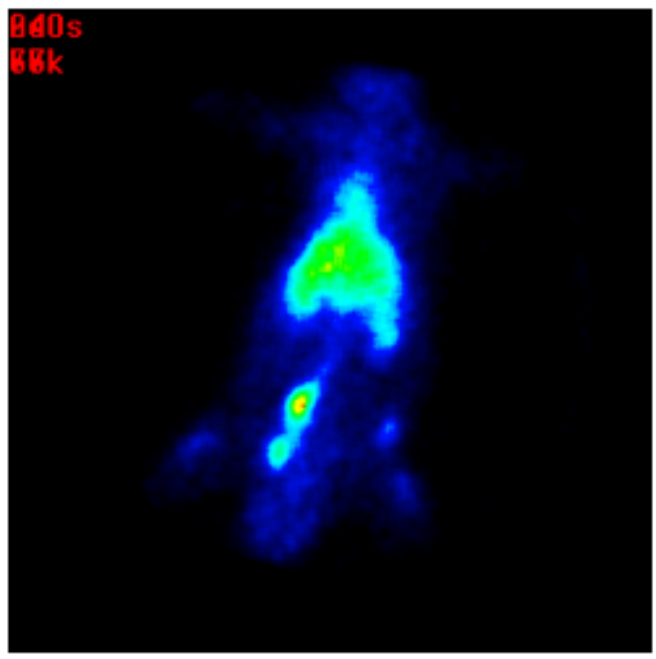

(6-b)

\section{Figure 6}

Whole body scintigraphy images of the rat after 15 minutes (6-a) and 45 minutes (6-b) post injection of labeled toxic fraction. Thyroid and stomach uptake level was low indicating good quality of the radiolabeled compound. 